\title{
Ressuscitação cardiopulmonar na gestação: uma revisão integrativa
}

\section{Cardiopulmonary resuscitation in pregnancy: an integrative review}

Cássia Regina Vancini-Campanharo', Meiry Fernanda Pinto Okuno ${ }^{1}$, Maria Carolina Barbosa Teixeira Lopes ${ }^{1}$, Ruth Ester Assayag Batista ${ }^{1}$, Maria Cristina Gabrielloni', Felipe Favorette Campanharo², Claudio Andre Barbosa de Lira ${ }^{3}$, Rodrigo Luiz Vancini ${ }^{4}$

${ }^{1}$ Escola Paulista de Enfermagem, Universidade Federal de São Paulo (UNIFESP) - São Paulo (SP), Brasil.

2Escola Paulista de Medicina, UNIFESP - São Paulo (SP), Brasil.

${ }^{3}$ Setor de Fisiologia Humana e do Exercício, Faculdade de Educação Física e Dança, Universidade Federal de Goiás (UFG) - Jataí (GO), Brasil.

${ }^{4}$ Centro de Educação Física e Desportos, Universidade Federal do Espírito Santo (UFES) - Vitória (ES), Brasil.

DOI: http://dx.doi.org/10.7322/abcshs.v41i3.909

\section{RESUMO}

O objetivo deste estudo foi identificar dados sobre atendimento à parada cardiorrespiratória na gestação. Foi realizada uma revisão integrativa de artigos publicados entre 2010 e 2015, em português, inglês e espanhol com a utilização dos seguintes descritores: "Parada Cardíaca"; "Ressuscitação Cardiopulmonar"; "Gestante" e "Gestação", nas seguintes bases de dados: MEDLINE, LILACS, IBECS e CUMED. A idade gestacional variou de 10 a 41 semanas, as etiologias mais comuns da parada cardiorrespiratória foram embolia pulmonar e trauma, os ritmos foram fibrilação ventricular e atividade elétrica sem pulso e o tempo em parada cardiorrespiratória variou de 15 a 60 minutos. O tratamento foi ressuscitação cardiopulmonar, intubação, administração de epinefrina e cesárea de emergência. Os desfechos mais observados nas mães e recém-nascidos foram alta e bom estado neurológico. Conclui-se que protocolos de atendimento específicos podem respaldar e auxiliar a tomada de decisão da equipe durante a ressuscitação cardiopulmonar, aumentando a sobrevida e diminuindo o dano neurológico nestas pacientes.

Palavras-chave: parada cardíaca; ressuscitação cardiopulmonar; gravidez.

\section{ABSTRACT}

The objective of this study was to identify data of compliance in cardiac arrest during pregnancy. An integrative review of articles published between 2010 and 2015 in Portuguese, English and Spanish using the following descriptors: "Cardiac Arrest"; "Cardiopulmonary Resuscitation"; "Pregnant" and "Pregnancy" was perfeormed in the following databases: MEDLINE, LILACS, IBECS and CUMED. The gestational age ranged from 10 to 41 weeks, the most common etiologies of cardiopulmonary arrest were pulmonary embolism and trauma, the rhythms were ventricular fibrillation and pulseless electrical activity and the time in cardiac arrest ranged from 15 to 60 minutes. Treatment was cardiopulmonary resuscitation, intubation, administration of epinephrine and emergency cesarean section. The outcomes observed in more mothers and newborns were hospital discharge and good neurological status. In conclusion, specific care protocols can endorse and assist the team's decision-making during cardiopulmonary resuscitation, increasing survival and decreasing neurological damage in these patients.

Keywords: heart arrest; cardiopulmonary resuscitation; pregnancy. 


\section{INTRODUÇÃO}

A ocorrência de parada cardiorrespiratória (PCR) é frequente e apresenta-se como um evento potencialmente fatal ${ }^{1}$. A PCR é a principal causa de morte na América do Norte, afetando mais de 450 mil pessoas a cada ano ${ }^{2}$. Nos países europeus, em ambiente extrahospitalar, é responsável por 350 mil mortes ${ }^{3}$. No Brasil, dados sobre mortalidade após PCR ainda são escassos. Atualmente, sabe-se que, em nosso país, as doenças cardiovasculares, as quais podem resultar em arritmias malignas e PCR, respondem por 250 mil mortes anuais ${ }^{4}$.

A PCR pode ser definida como a interrupção da atividade mecânica cardíaca, confirmada pela ausência de responsividade, apnéia ou respiração agônica e ausência de sinais de circulação. As possíveis causas mais comuns de PCR podem ser divididas em cardíacas (síndromes coronarianas agudas, arritmias, miocardiopatias e valvulopatias) e não cardíacas (acidente vascular encefálico, embolia pulmonar, obstrução das vias aéreas e o abuso de substâncias) ${ }^{5}$.

As medidas gerais de tratamento da PCR baseiam-se em uma sequência ideal de ações que devem ser adotadas imediatamente após o reconhecimento do início de um "mal súbito". A corrente da sobrevivência, como é conhecida essa sequência de prioridades, consiste do reconhecimento precoce dos sinais e sintomas de um ataque cardíaco ou de deterioração hemodinâmica e o acesso rápido a um serviço médico de emergência, da realização precoce de manobras de ressuscitação cardiopulmonar (RCP) e da desfibrilação, do acesso rápido as medidas de suporte avançado de vida e da administração de cuidados pós-PCR, os quais podem melhorar as funções cerebral, cardíaca e pulmonar ${ }^{5,6}$.

Além das medidas gerais de tratamento, existem situações específicas, denominadas "situações especiais". Dentre elas estão o atendimento de vítimas com asma, anafilaxia, obesidade mórbida, embolia pulmonar, distúrbio hidroeletrolítico, ingestão de substâncias tóxicas, trauma, hipotermia acidental, avalanche, afogamento, choque elétrico/relâmpagos, intervenção coronária percutânea, tamponamento cardíaco, cirurgia cardíaca e gestação. A PCR em situações especiais pode exigir abordagens e procedimentos específicos além daqueles executados durante o atendimento de suporte básico e avançado de vida ${ }^{7,8}$.

Com relação à gestação, as mudanças fisiológicas associadas ao estado gravídico contribuem para um aumento no risco de PCR nestas pacientes 9 . Tais alterações incluem o aumento da volemia circulante com desproporção entre plasma e hemácias, ocasionando "anemia" fisiológica, incremento do débito cardíaco decorrente da necessidade de perfusão do útero gravídico, elevação do diafragma por compressão uterina com desvio do eixo cardíaco e alteração dos volumes pulmonares, com consequente alcalose respiratória compensada, relaxamento do esfíncter gastroesofágico inferior e atraso no esvaziamento gástrico, ocasionando aumento do risco de aspiração, edema nasal e traqueal, por aumento do fluxo sanguíneo, além de produção aumentada de saliva, o que podem dificultar a visualização das vias aéreas e a compressão da veia cava pelo útero, o que diminui o retorno venoso 9 .
As mesmas causas reversíveis de PCR em mulheres não grávidas podem ocorrer em mulheres grávidas, mas devem ser consideradas as causas específicas desta população como a intoxicação de sulfato de magnésio, as síndromes coronarianas agudas, a pré-eclâmpsia, dissecção aórtica, embolia pulmonar, acidente vascular encefálico, embolia amniótica, trauma e overdose de drogas ${ }^{10}$.

Algumas manobras básicas durante a RCP de uma gestante são recomendadas. Dentre elas, colocar a paciente em decúbito lateral esquerdo, fornecer oxigênio a $100 \%$, considerar causas reversíveis de PCR e identificar qualquer condição que possa dificultar a RCP. Além disso, deve-se considerar a existência de dois pacientes em potencial, o binômio materno-fetal. A realização de cesárea de emergência, com início no quarto minuto após o colapso, melhora as chances de sobrevivência da mãe e do feto. A retirada do concepto esvazia o útero, melhorando o retorno venoso e a compressão aórtica, possibilitando ainda a realização de RCP, se necessária ${ }^{10}$.

A existência de diretrizes estabelecidas para o manejo dos pacientes com PCR necessita de atualização constante. A American Heart Association (AHA) juntamente com a International Liason Comittee on Resuscitation (ILCOR) reúnem, a cada cinco anos, as melhores evidências para o manejo das emergências cardiovasculares e da PCR 6 .

Apesar dos avanços no desenvolvimento de técnicas de RCP, do acesso precoce à desfibrilação externa automática e da introdução de novos agentes farmacológicos para o tratamento da PCR, a mortalidade não apresentou queda significativa nas últimas décadas, sendo que poucos indivíduos sobrevivem à alta hospitalar e com índices elevados de morbidade e sequelas neurológicas ${ }^{11}$.

As taxas de sobrevida e o prognóstico são variáveis, principalmente, devido à heterogeneidade da população atendida. A RCP de qualidade bem como os cuidados pós-PCR são fundamentais para que ocorra bom desfecho para a paciente e seu concepto. Além disso, o entendimento das possíveis causa de PCR maternal e dos eventos fisiológicos próprios da gravidez podem determinar adaptações nas condutas no suporte básico e avançado de vida na gestante, aumentando as chances de sobrevida para o binômio materno-fetal em bom estado neurológico.

Tivemos como objetivo: Identificar na literatura as variáveis relacionadas à PCR durante a gestação: idade gestacional, provável etiologia, ritmo inicial, medidas terapêuticas utilizadas, tempo de PCR e desfecho materno e neonatal pós-PCR.

\section{MÉTODOS}

Trata-se de uma revisão integrativa da literatura sobre a ocorrência de PCR e a realização de manobras de RCP durante a gestação ${ }^{12}$.

Na estratégia de busca desta pesquisa, foram utilizados os seguintes descritores: "parada cardíaca"; "ressuscitação cardiopulmonar"; "gestante" e "gestação", associados pela lógica booleana AND. 
Os artigos foram pesquisados no portal de busca da Biblioteca Virtual em Saúde (BIREME) nas bases de dados: Literatura Internacional em Ciências da Saúde (MEDLINE), Literatura Latino-Americana e do Caribe em Ciências da Saúde (LILACS), índice Bibliográfico Espanhol de Ciências da Saúde (IBECS) e Biblioteca Virtual em Saúde de Cuba (CUMED).

- Critérios de inclusão: foram selecionados artigos que abordavam a ocorrência de PCR durante a gestação e a realização de manobras de RCP; nos idiomas português, inglês e espanhol, publicados no período de 2010 a 2015. Devido à escassez de publicações referentes ao assunto, foram considerados resumos de artigos não disponíveis na íntegra.

- Critérios de exclusão: foram excluídos artigos em duplicidade nas bases de dados, editoriais, cartas ao editor, correspondências, revisões da literatura e guidelines referentes ao assunto.

Desta forma, respeitando as normas de exclusão, a amostra final foi composta por 18 artigos. Para análise dos artigos, foi utilizado um instrumento de coleta de dados, contemplando as seguintes informações: ano de publicação, autor, país, tipo do estudo, amostra e as variáveis da PCR: idade gestacional, provável etiologia, ritmo inicial, medidas terapêuticas utilizadas, tempo de PCR e desfecho materno e neonatal pós-PCR.

A análise dos dados ocorreu de forma organizada e crítica, à medida que se realizou leitura aprofundada dos conteúdos, buscando esclarecimentos a respeito do tema ${ }^{13}$.

\section{RESULTADOS}

Após a utilização da estratégia de busca desta pesquisa foram encontrados 246 artigos, sendo que destes foram selecionados 18 artigos (Tabela 1).

Em relação ao ano de publicação, cinco artigos foram publicados no ano de 2013, seis em 2012, cinco artigos em 2011 e dois em 2010. Não foram encontrados artigos dos anos de 2014 e 2015 que

Tabela 1: Literatura selecionada na biblioteca virtual em saúde de 2010-2015 sobre gestação e parada cardiorrespiratória e gestação e ressuscitação cardiopulmonar

\begin{tabular}{|l|c|c|c|}
\hline Descritores & $\begin{array}{c}\text { Base de } \\
\text { dados }\end{array}$ & $\begin{array}{c}\text { Artigos } \\
\text { encontrados }\end{array}$ & $\begin{array}{c}\text { Artigos } \\
\text { selecionados }\end{array}$ \\
\hline "Parada Cardíaca" & LILACS & 2 & 1 \\
\hline AND "Gestante" & CUMED & 1 & 0 \\
\hline "Parada Cardíaca" & LILACS & 5 & 2 \\
\hline AND "Gestação" & MEDLINE & 152 & 15 \\
\hline IBECS & 2 & 0 \\
\hline "Ressuscitação & LILACS & 2 & 0 \\
\hline Cardiopulmonar" & CUMED & 1 & 0 \\
\hline AND "Gestante" & LILACS & 3 & 0 \\
\hline "Ressuscitação & MEDLINE & 73 & 0 \\
\hline Cardiopulmonar" & IBECS & 4 & 0 \\
\hline AND "Gestação" & CUMED & 1 & 18 \\
\hline Total & & 246 & \\
\hline
\end{tabular}

preenchiam os critérios de inclusão do estudo. Os países de realização dos estudos foram: Estados Unidos (três estudos), França, Canadá, Alemanha e Bélgica (dois estudos) e Nigéria, Japão, Turquia, Argentina, China, Croácia e Holanda (um estudo). Do total de estudos ( $n=18), 16$ foram relatos de caso, realizados com uma ou duas gestantes, um foi uma série de casos, com cinco gestantes e um estudo de coorte retrospectivo, realizado com 12 gestantes (Tabela 2).

Nos estudos selecionados, a idade gestacional variou de 10 a 41 semanas de gestação, sendo que as prováveis etiologias de PCR mais comuns foram embolia pulmonar e trauma. Outras possíveis causas mencionadas foram: anestesia, cardiomiopatia, hipóxia, síndrome anafilática da gravidez, gastrotórax hipertensivo, edema pulmonar e infarto do miocárdio (Tabela 3).

Os ritmos iniciais de PCR mais comuns foram a fibrilação ventricular e atividade elétrica sem pulso. Além disso, foram relatados dois casos de assistolia e em 11 casos o ritmo inicial não foi mencionado no estudo (Tabela 3 ).

Em relação às medidas terapêuticas empregadas no atendimento à PCR, as mais citadas foram: RCP, intubação orotraqueal, administração de epinefrina e a cesárea de emergência, realizada com tempo variando de dois a 45 minutos após a PCR. O tempo de PCR variou de 15 a 60 minutos nos casos em que este dado foi mencionado (Tabela 3 ).

Os desfechos maternos e fetais mais observados nos estudos foram alta hospitalar em bom estado neurológico (Tabela 4).

Tabela 2: Distribuição dos artigos segundo ano e autor, país, tipo do estudo e número de sujeitos

\begin{tabular}{|c|c|c|c|}
\hline Estudos & $\begin{array}{l}\text { País do } \\
\text { estudo }\end{array}$ & $\begin{array}{l}\text { Tipo do } \\
\text { estudo }\end{array}$ & $\begin{array}{l}\text { Número de } \\
\text { sujeitos }\end{array}$ \\
\hline 2013, Osazuwa ${ }^{14}$ & Nigéria & Relato de caso & 1 \\
\hline 2013, Brun et al..$^{15}$ & França & Relato de caso & 1 \\
\hline 2013, Hikiji et al..$^{16}$ & Japão & Relato de caso & 1 \\
\hline 2013, Chauhan et al. ${ }^{17}$ & $\begin{array}{l}\text { Estados } \\
\text { Unidos }\end{array}$ & Relato de caso & 1 \\
\hline 2013, Baghirzada ${ }^{18}$ & Canadá & Série de casos & 5 \\
\hline 2012, Grimme et al. ${ }^{19}$ & Alemanha & Relato de caso & 1 \\
\hline 2012, Franchitto 20 & França & Relato de caso & 1 \\
\hline 2012, Farinelli et al. ${ }^{21}$ & $\begin{array}{l}\text { Estados } \\
\text { Unidos }\end{array}$ & Relato de caso & 1 \\
\hline 2012, Jacobs et al. ${ }^{22}$ & Bélgica & Relato de caso & 1 \\
\hline 2012, Guven et al. ${ }^{23}$ & Turquia & Relato de caso & 2 \\
\hline 2012, Flameé et al. ${ }^{24}$ & Bélgica & Relato de caso & 1 \\
\hline 2011, Matera et al. ${ }^{25}$ & Argentina & Relato de caso & 1 \\
\hline 2011, Wenk et al. ${ }^{26}$ & Alemanha & Relato de caso & 1 \\
\hline 2011, Engels et al. ${ }^{27}$ & Canáda & Relato de caso & 1 \\
\hline 2011, Wei et al..$^{28}$ & China & Relato de caso & 1 \\
\hline 2011, Babic et al. ${ }^{29}$ & Croácia & Relato de caso & 1 \\
\hline 2010, Wible et al..$^{30}$ & $\begin{array}{l}\text { Estados } \\
\text { Unidos }\end{array}$ & Relato de caso & 1 \\
\hline 2010, Dijkman et al. ${ }^{31}$ & Holanda & $\begin{array}{c}\text { Coorte e } \\
\text { retrospectivo }\end{array}$ & 12 \\
\hline
\end{tabular}




\section{DISCUSSÃO}

Apesar dos avanços nas técnicas de RCP, do uso precoce do desfibrilador externo automático e da instituição de medidas de suporte avançado de vida, a mortalidade na população geral por PCR permanece alta e a sobrevida associada a importantes sequelas neurológicas ${ }^{11}$.
A gestação impõe ao corpo materno mudanças fisiológicas, como o aumento das demandas metabólicas, a compressão aórtica e da veia cava pelo útero gravídico e o risco aumentado de hipovolemia, o que implica em maior chance de sofrer uma PCR, apesar de ser um evento raro nesta população ${ }^{10}$.

Tabela 3: Distribuição dos artigos segundo ano e autor, idade gestacional, provável etiologia e ritmo inicial da parada cardiorrespiratória e medidas terapêuticas utilizadas

\begin{tabular}{|c|c|c|c|c|c|}
\hline $\begin{array}{l}\text { Ano, } \\
\text { Autor }\end{array}$ & $\begin{array}{l}\text { Idade gestacional } \\
\text { (semanas) }\end{array}$ & $\begin{array}{l}\text { Provável } \\
\text { etiologia }\end{array}$ & $\begin{array}{l}\text { Ritmo } \\
\text { inicial }\end{array}$ & $\begin{array}{l}\text { Medidas } \\
\text { terapêuticas }\end{array}$ & $\begin{array}{c}\text { Tempo de } \\
\text { parada } \\
\text { (minutos) }\end{array}$ \\
\hline $\begin{array}{l}2013 \\
\text { Osazuwa }^{14}\end{array}$ & ND & Anestesia & ND & $\mathrm{RCP}$, oxigênio e epinefrina & ND \\
\hline $\begin{array}{l}2013 \\
\text { Brun et al. }{ }^{15}\end{array}$ & Desconhecida & Trauma & AESP & $\begin{array}{l}\text { RCP, IOT, epinefrina, volume } \\
\text { e DLE }\end{array}$ & 30 \\
\hline $\begin{array}{l}2013 \text {, } \\
\text { Hikiji et al. }{ }^{16}\end{array}$ & 40 & Embolia pulmonar & ND & $\mathrm{RCP}$ & ND \\
\hline $\begin{array}{l}2013 \text {, } \\
\text { Chauhan et al. }{ }^{17}\end{array}$ & 20 & Cardiomiopatia & FV & $\begin{array}{l}\mathrm{RCP}, \mathrm{IOT} \text {, epinefrina, } \\
\text { atropina e hipotermia } \\
\text { terapêutica }\end{array}$ & 25 \\
\hline \multirow{5}{*}{$\begin{array}{l}\text { 2013, } \\
\text { Baghirzada }^{18}\end{array}$} & 33 & Embolia pulmonar & AESP & RCP, CE no $14^{\circ} \mathrm{min}$. & 25 \\
\hline & 41 & Embolia pulmonar & AESP & $\mathrm{RCP}, \mathrm{CE} 2^{\circ}$ no $\min$. & ND \\
\hline & 27 & Desconhecido & Assistolia & $\mathrm{RCP}, \mathrm{CE}$ no $31^{\circ} \mathrm{min}$. & ND \\
\hline & 27 & Embolia pulmonar & FV & $\mathrm{RCP}, \mathrm{CE}$ no $6^{\circ} \mathrm{min}$. & ND \\
\hline & 38 & Desconhecido & AESP & RCP, CE no $14^{\circ}$ min. & 16 \\
\hline $\begin{array}{l}2012, \\
\text { Grimme et al. }{ }^{19}\end{array}$ & 19 & Hipóxia & ND & $\mathrm{RCP}$ & ND \\
\hline $\begin{array}{l}2012, \\
\text { Franchitto }{ }^{20}\end{array}$ & 39 & Embolia pulmonar & FV & RCP, IOT e CE & ND \\
\hline $\begin{array}{l}2012 \text {, } \\
\text { Farinelli et al. } .^{21}\end{array}$ & 38 & $\begin{array}{c}\text { Síndrome anafilática da } \\
\text { gravidez }\end{array}$ & ND & RCP e CE no $5^{\circ} \min$. & ND \\
\hline $\begin{array}{l}\text { 2012, } \\
\text { Jacobs et al. }{ }^{22}\end{array}$ & ND & Gastrotórax hipertensivo & ND & $\mathrm{RCP}$ & 60 \\
\hline \multirow{2}{*}{$\begin{array}{l}\text { 2012, } \\
\text { Guven et al. }{ }^{23}\end{array}$} & 37 & Trauma & ND & $\mathrm{RCP}$ e CE no $45^{\circ} \mathrm{min}$. & ND \\
\hline & 31 & Trauma & ND & $\mathrm{RCP}$ e CE no $15^{\circ} \mathrm{min}$. & ND \\
\hline $\begin{array}{l}2012, \\
\text { Flameé et al. }{ }^{24}\end{array}$ & 21 & Gastrotórax hipertensivo & ND & $\begin{array}{l}\text { RCP, IOT, toracocentese de } \\
\text { alívio e drenagem torácica }\end{array}$ & ND \\
\hline $\begin{array}{l}2011, \\
\text { Matera et al. }{ }^{25}\end{array}$ & 28 & ND & ND & RCP, CE no $15^{\circ} \mathrm{min}$. & 15 \\
\hline $\begin{array}{l}\text { 2011, } \\
\text { Wenk et al. }{ }^{26}\end{array}$ & 33 & Embolia pulmonar & Assistolia & $\begin{array}{l}\text { RCP, epinefrina, trombolítico } \\
\text { e hipotermia terapêutica }\end{array}$ & 36 \\
\hline $\begin{array}{l}\text { 2011, } \\
\text { Engels et al. }{ }^{27}\end{array}$ & 37 & Edema pulmonar & AESP & $\begin{array}{l}\text { RCP, epinefrina, atropina, } \\
\text { bicarbonato de sódio e CE } \\
\text { no } 8^{\circ} \text { min. }\end{array}$ & 38 \\
\hline $\begin{array}{l}\text { 2011, } \\
\text { Wei et al. }{ }^{28}\end{array}$ & 37 & Embolia pulmonar & ND & $\begin{array}{l}\text { RCP, IOT, epinefrina, } \\
\text { volume, oxigenação por } \\
\text { membrana extracorpórea }\end{array}$ & ND \\
\hline $\begin{array}{l}\text { 2011, } \\
\text { Babic et al. }{ }^{29}\end{array}$ & 10 & Infarto do miocárdio & FV & RCP e angioplastia & ND \\
\hline $\begin{array}{l}2010 \text {, } \\
\text { Wible et al. } .^{30}\end{array}$ & 20 & ND & FV & $\begin{array}{l}\mathrm{RCP} \text { e hipotermia } \\
\text { terapêutica }\end{array}$ & ND \\
\hline $\begin{array}{l}\text { 2010, } \\
\text { Dijkman et al. }{ }^{31}\end{array}$ & $29-40$ & Embolia pulmonar & ND & $\mathrm{RCP}$ e CE do $5^{\circ}$ ao $31^{\circ} \mathrm{min}$. & ND \\
\hline
\end{tabular}

ND: Não disponível; RCP: Ressuscitação cardiopulmonar; AESP: Atividade elétrica sem pulso; IOT: Intubação orotraqueal; DLE: Decúbito lateral esquerdo; FV: Fibrilação ventricular; min.: Minutos; CE: Cesárea de emergência. 
Tabela 4: Distribuição dos artigos segundo desfecho e estado neurológico materno e fetal

\begin{tabular}{|c|c|c|c|c|}
\hline Ano, Autor & $\begin{array}{l}\text { Desfecho } \\
\text { materno }\end{array}$ & $\begin{array}{c}\text { Estado neurológico } \\
\text { materno }\end{array}$ & $\begin{array}{l}\text { Desfecho } \\
\text { fetal }\end{array}$ & $\begin{array}{c}\text { Estado } \\
\text { neurológico fetal }\end{array}$ \\
\hline 2013, Osazuwa ${ }^{14}$ & Alta & Bom & ND & ND \\
\hline 2013, Brun et al. ${ }^{15}$ & Óbito & - & Óbito & - \\
\hline 2013, Hikiji et al. ${ }^{16}$ & Óbito & - & Óbito & - \\
\hline 2013, Chauhan et al. ${ }^{17}$ & Alta & Bom & Alta & Bom \\
\hline \multirow{5}{*}{ 2013, Baghirzada ${ }^{18}$} & Alta & Bom & Alta & Bom \\
\hline & Alta & Bom & Alta & Bom \\
\hline & Óbito & - & - & - \\
\hline & Óbito & - & Alta & Bom \\
\hline & Alta & Bom & Alta & Bom \\
\hline 2012, Grimme et al. ${ }^{19}$ & Alta & Bom & ND & ND \\
\hline 2012, Franchitto ${ }^{20}$ & Óbito & - & Alta & Bom \\
\hline 2012, Farinelli et al. ${ }^{21}$ & Alta & Déficit neurológico mínimo & ND & ND \\
\hline 2012, Jacobs et al. ${ }^{22}$ & Alta & Bom & ND & ND \\
\hline \multirow{2}{*}{ 2012, Guven et al. ${ }^{23}$} & Óbito & - & Alta & Déficit neurológico \\
\hline & Óbito & - & Alta & Bom \\
\hline 2012, Flameé et al. ${ }^{24}$ & ND & ND & - & - \\
\hline 2011, Matera et al. ${ }^{25}$ & Alta & Tetraparesia flácida & Óbito & - \\
\hline 2011, Wenk et al. ${ }^{26}$ & Alta & Bom & Alta & Bom \\
\hline 2011, Engels et al. ${ }^{27}$ & Óbito & - & Óbito & - \\
\hline 2011, Wei et al. ${ }^{28}$ & Alta & Bom & - & - \\
\hline 2011, Babic et al. ${ }^{29}$ & Alta & Bom & - & - \\
\hline 2010, Wible et al. ${ }^{30}$ & Alta & Bom & Óbito & - \\
\hline 2010, Dijkman et al. ${ }^{31}$ & Alta & Bom & Alta & Bom \\
\hline
\end{tabular}

ND: Não disponível

A maioria dos estudos encontrados na estratégia de busca desta revisão abordou a ocorrência de PCR e a realização de RCP após o parto, o que limitou o número de estudos selecionados para esta revisão. Além disso, a grande maioria dos estudos selecionados foram relatos ou séries de casos, o que limita a retirada de conclusões, uma vez que a amostra de pacientes foi muito pequena ${ }^{14-30}$.

As causas de PCR mencionadas nos estudos que fizeram parte desta revisão, em sua maioria, foram causas cardiovasculares, as quais não diferem muito da população geral, sendo que a embolia pulmonar, foi a causa mais encontrada de PCR nesta população ${ }^{16-18,20,26,28,31}$. Além disso, os ritmos de PCR fibrilação ventricular e atividade elétrica sem pulso ${ }^{15-17,19,27,29,30}$ foram os mais encontrados, achado que condiz com a população em geral, uma vez que as doenças cardiovasculares são as mais frequentes no mundo e no Brasil e que estas podem evoluir para arritmias malignas como nestes casos ${ }^{7}$.

Em relação às medidas terapêuticas adotadas nos casos de PCR na gestação, as mais citadas foram a realização de RCP, com compressões torácicas externas, ventilação com oxigênio a $100 \%$, a realização de desfibrilação e administração de epinefrina ${ }^{14-31}$ - medidas essas preconizadas para o atendimento da população em geral $^{32}$.

Além da realização de cesárea de emergência ${ }^{18-23,25,27,31}$, preconizada até o quarto minuto após PCR, o deslocamento uterino para esquerda é uma manobra que alivia a compressão aórtica e da veia cava e melhorando a qualidade da RCP, proporcionando maiores chances de retorno à circulação espontânea.?

A administração de trombolíticos ${ }^{26}$, intervenção coronariana percutânea ${ }^{30}$, oxigenação por membrana extracorpórea ${ }^{29} \mathrm{e}$ toracocentese de alívio seguida de drenagem torácica ${ }^{24}$ foram utilizadas como medidas terapêuticas em situações específicas, como na população geral ${ }^{7}$, podendo relacionar-se a ocorrência de alta materna em bom estado neurológico.

As diretrizes de atendimento à PCR e às emergências cardiovasculares mencionam a gestação como uma situação especial, devido às mudanças fisiológicas no corpo materno, o que implica na realização de compressões torácicas com descompressão manual do útero sobre a circulação sistêmica e cesárea de emergência precoce, o que melhorar as chances de sobrevida da mãe e do feto ${ }^{7}$. 
Com o objetivo de diminuir o dano neurológico causado pelo processo de hipóxia e reperfusão, as diretrizes de atendimento enfatizam o uso da hipotermia terapêutica em pacientes comatosos após retorno à circulação espontânea. Em gestantes não há evidências científicas que corroborem com esta recomendação ${ }^{7}$. Entretanto, nesta revisão foram encontrados três estudos nos quais a hipotermia terapêutica foi utilizada. Em dois deles a idade gestacional materna foi 20 e 33 semanas, sendo que mãe e recém-nascido tiveram alta hospitalar em bom estado neurológico ${ }^{17,26}$. No terceiro, a idade gestacional foi de 20 semanas, sendo que a mãe evoluiu para alta hospitalar em bom estado neurológico e o feto para óbito ${ }^{30}$.

O desfecho final destes pacientes, tanto da mãe como do feto, dependem do treinamento constante da equipe no atendimento a estas situações de emergência. Os estudos selecionados para esta revisão evidenciaram o desfecho alta materna e fetal com bom prognóstico neurológico na maioria dos $\operatorname{casos}^{14,16-19,21,22,25,26,28-32}$, o que pode estar relacionado a ocorrência de PCR em pessoas previamente hígidas, em ambiente intrahospitalar, com início da RCP precoce e realização precoce da cesárea de emergência.
A assistência imediata e multiprofissional durante os esforços de RCP é fundamental para o acionamento da cadeia de sobrevivência e boa condução do atendimento. A existência de protocolos de atendimento pode respaldar e auxiliar a tomada de decisão da equipe durante a RCP e, desta forma, aumentar a sobrevida e diminuir o dano neurológico nestes indivíduos.

Esta revisão sugere mais estudos, com maior nível de evidência, nesta população, pois o número de pacientes ainda é limitado.

\section{CONCLUSÃO}

Os resultados encontrados demonstraram que a idade gestacional das gestantes que sofreram PCR variou de 10 a 41 semanas, as causas prováveis mais comuns de PCR foram embolia pulmonar e trauma, os ritmos iniciais de PCR mais encontrados foram AESP e FV e o tempo de PCR variou de 15 a 60 minutos.

As medidas terapêuticas mais realizadas nestas pacientes foram a RCP, intubação orotraqueal e administração de epinefrina.

\section{REFERÊNCIAS}

1. Schneider A, Bottiger BW, Popp E. Cerebral resuscitation after cardiocirculatory arrest. Anesth Analg. 2009;108(3):971-9 http://dx.doi.org/10.1213/ane.0b013e318193ca99

2. Rittenberger JC, Guyette FX, Tisherman SA, DeVita MA, Alvarez RJ, Callaway CW. Qutcomes of a hospital-wide plan to improve care of comatose survivors of cardiac arrest. Resuscitation. 2008;79(2):198-204.

http://dx.doi.org/1016/j.resuscitation.2008.08.014

3. Timerman S, Ramires JAF. Morte súbita: aspectos epidemiológicos. Rev Soc Cardiol. Estado São Paulo. 2006;16(1):8-23.

4. Popp E, Bottiger BW. Cerebral Resuscitation: State of the art, experimental approaches and clinical perspectives. Neurol Clin. 2006;24(1):73-87.

http://dx.doi.org/10.1016/j.ncl.2005.10.008

5. Aehlert B. Advanced Cardiac Life Support (ACLS). $3^{\text {a }}$ ed. Rio de Janeiro: Elsevier; 2007; p.591.

6. Neumar RW, Otto CW, Link MS, Kronick SL, Shuster M, Callaway CW, et al. Part 8: Adult Advanced Cardiovascular Life Support: 2010 American Heart Association Guidelines for Cardiopulmonary Resuscitation and Emergency Cardiovascular Care. Circulation. 2010;122(18 Suppl 3);S729-67.

http://dx.doi.org/10.1161/CIRCULATIONAHA.110.970988

7. Neumar RW, Shuster M, Callaway CW, Gent LM, Atkins DL, Bhanji $F$, et al. Part 1: Executive Summary: 2015 American Heart Association Guidelines Update for Cardiopulmonary Resuscitation and Emergency Cardiovascular Care. Circulation. 2015;132(18 Suppl 2):S315-67. http://dx.doi.org/10.1161/CIR.0000000000000252

8. Banks A. Maternal resuscitation: plenty of room of improvement. Int J Obstetr Anesthesia. 2008;17(4):289-91. http://dx.doi.org/10.1016/j.ijoa.2008.07.008
9. Schimmelpfennig K, Stanfill T. When lightening strikes: preparing for maternal cardiac arrest. One hospital's journey. AWHONN lifelines. 2006:10(4):306-11

http://dx.doi.org/10.1111/j.1552-6356.2006.00053.x

10. Braga A, Trindade AP, Soggia MEV, Boccaletti MC, Asmar FTC Rezende-Filho J, et al. Colapso materno - Conduta da parada cardíaca na gravidez. Femina. 2012;40(4):209-16.

11. Safar PJ, Kochanek PM. Therapeutic hypothermia after cardiac arrest. N Engl J Med. 2002;346(8):612-3. http://dx.doi.org/10.1056/NEJM200202213460811

12. Mendes KDS, Silveira RCCP, Galvão CM. Revisão integrativa: método de pesquisa para a incorporação de evidencias na saúde e na enfermagem. Texto Contexto Enferm. 2008 17(4):758-64. http://dx.doi.org/10.1590/S0104-07072008000400018

13. Severino AJ. Metodologia do trabalho científico. São Paulo: Cortez; 2002.

14. Osazuwa MO. Cardiac arrest following spinal anaesthesia for Caesarean section: a case report. West Afr J Med. 2013;32(2):145-8.

15. Brun PM, Chenaitia H, Dejesus I, Bessereau J, Bonello L, Bouzat P. Ultrasound to perimortem caesarean delivery in prehospital settings. Injury. 2013;44(1):151-2. http://dx.doi.org/10.1016/j.injury.2012.08.029

16. Hikiji W, Tamura N, Shigeta A, Kanayama N, Fukunaga T. Fatal amniotic fluid embolism with typical pathohistological, histochemical and clinical features. Forensic Sci Int. 2013;226(1-3):e16-19. http://dx.doi.org/10.1016/j.forsciint.2012.12.008

17. Chauhan A, Musunuru $H$, Donnino M, McCurdy MT, Chauhan V Walsh M. The Use of Therapeutic Hypothermia After Cardiac Arrest in a Pregnant Patient. Ann Emerg Med. 2012;60(6):786-89. http://dx.doi.org/10.1016/..annemergmed.2012.06.004 
18. Baghirzada L, Balki M. Maternal cardiac arrest in a tertiary care centre during 1989-2011: a case series. Can J Anesth. 2013;60(11):1077-84.

http://dx.doi.org/10.1007/s12630-013-0021-9

19. Grimme I, Winter R, Kluge S, Petzoldt M. Hypoxic cardiac arrest in pregnancy due to pulmonary haemorrhage. BMJ Case Reports. 2012.

http://dx.doi.org/10.1136/bcr-2012-006741

20. Franchitto N, Minville V, Fabrice D, Telmon N, Roug D. Medical Responsibility in the Operating Room: The Example of an Amniotic Fluid Embolism. J Forensic Sci. 2012;57(4):1120-3. http://dx.doi.org/10.1111/j.1556-4029.2012.02098.x

21. Farinelli CK, Hameed AB. Cardiopulmonary resuscitation in pregnancy. Cardiol Clin. 2012;30:453-61. http://dx.doi.org/10.1016/j.ccl.2012.04.006

22. Jacobs R, Honore PM, Hosseinpour N, Nieboer K, Spapen HD. Sudden cardiac arrest during pregnancy: a rare complication of acquired maternal diaphragmatic hernia. Acta Clin Belg. 2012;67(3): 198-200.

http://dx.doi.org/10.1179/ACB.67.3.2062655

23. Guven S, Yazar A, Yakut K, Aydogan H, Erguven M, Avci E. Postmortem cesarean: report of our successful neonatal outcomes after severe trauma during pregnancy and review of the literature. J Matern Fetal Neonatal Med. 2012;25(7):1102-4. http://dx.doi.org/10.3109/14767058.2011.622419

24. Flameé P, Pregardien C. Tension gastrothorax causing cardiac arrest. CMAJ. 2012;184(1):E82 http://dx.doi.org/10.1503/cmaj.110715

25. Matera MC. Cesárea perimortem: a propósito de un caso. Rev Hosp Mat Inf. Ramón Sardá. 2011;30(3):122-6.
26. Wenk M, Pöppingt DM, Hillyard S, Albers H, Möllmann M. Intraoperative thrombolysis in a patient with cardiopulmonary arrest undergoing caesarean delivery. Anaesth Intensive Care. 2011;39(4):671-4.

27. Engels PT, Caddy SC, Jiwa G, Matheson DJ. Cardiac arrest in pregnancy and perimortem cesarean delivery: case report and discussion. CJEM. 2011;13(6):399-403.

http://dx.doi.org/10.2310/8000.2011.110282

28. Wei J, Yang HS, Tsai SK, Hsiung MC, Chang CY, Ou CH, et al. Emergent bedside real-time three-dimensional transesophageal echocardiography in a patient with cardiac arrest following a caesarean section. Eur J Echocardiogr. 2011;12(3):E16. http://dx.doi.org/10.1093/ejechocard/jeq161

29. Babic Z, Gabric ID, Pintaric H. Successful primary percutaneous coronary intervention in the first trimester of pregnancy. Catheter Cardiovasc Interv. 2011;77(4):522-5 http://dx.doi.org/10.1002/ccd.22813

30. Wible EF, Kass JS, Lopez GA. A report of fetal demise during therapeutic hypothermia after cardiac arrest. Neurocrit Care. 2010;13(2):239-42.

http://dx.doi.org/10.1007/s12028-010-9395-5

31. Dijkman A, Huisman CMA, Smit M, Schutte JM, Zwart JJ, van Roosmalem JJ, et al. Cardiac arrest in pregnancy: increasing use of perimortem caesarean section due to emergency skills training? BJOG. 2010;117(3):282-7

http://dx.doi.org/10.1111/j.1471-0528.2009.02461.x

32. Link MS, Berkow LC, Kudenchuk PJ, Halperin HR, Hess EP, Moitra VK, et al. Part 7: Adult Advanced Cardiovascular Life Support: 2015 American Heart Association Guidelines Update for Cardiopulmonary Resuscitation and Emergency Cardiovascular Care. Circulation. 2015;132(18 Suppl 2): S444-64. http://dx.doi.org/10.1161/CIR.0000000000000261 